\title{
Review
}

\section{A brief history of sciatica}

\author{
JMS Pearce*,1 \\ ${ }^{1}$ Department of Neurology, Hull Royal Infirmary and Hull York Medical School, UK
}

Study design: Historical review.

Objectives: Appraise history of concept of sciatica.

Setting: Europe.

Methods: Selected, original quotations and a historical review.

Results: Evolution of ideas from hip disorders, through interstitial neuritis.

Conclusion: Current concepts of discogenic sciatica.

Sponsorship: None.

Spinal Cord (2007) 45, 592-596; doi:10.1038/sj.sc.3102080; published online 5 June 2007

Keywords: sciatica; intervertebral disc; disc prolapse

\section{Introduction}

Using selected, original quotations and a historical review, this paper attempts to appraise the several steps leading to modern concepts of the ubiquitous sciatica.

Pain in sciatic distribution was known and recorded by ancient Greek and Roman physicians, but was commonly attributed to diseases of the hip joint. Although graphic descriptions abounded, it was not until Cotugno's experiments of 1764 that leg pain of 'nervous' origin was distinguished from pain of 'arthritic' origin. In the nineteenth century, disc diseases including prolapse were recognised, but not related to sciatica until Lasègue described his sign to indicate stretching of the sciatic nerve. The first successful removal of a ruptured disc via laminectomy was probably in 1901 when Krause with Herman Oppenheim thought that they had removed an enchondroma. Bonomo proposed more limited access. Before the well-known clarification of nuclear disc herniation by Mixter and Barr in 1934, Vittorio Putti in 1927 recognised degenerative changes of the intervertebral foramen as a cause of sciatic nerve compression. Dandy in 1929, operated for low back and leg pain, finding cartilaginous fragments lying loose in the spinal canal. Many refinements of case selection and surgical techniques have subsequently evolved.

It is not always appreciated that an intervertebral disc lesion was only generally accepted as the commonest cause of sciatic pain in 1934 after Mixter and Barr's signal paper. ${ }^{1}$ The history of sciatica ${ }^{2}$ before this study is a long one.

*Correspondence: JMS Pearce, 304 Beverley Road Anlaby, East Yorks, HU10 7BG, England
Hippocrates was allegedly, the first physician to use the term 'sciatica', deriving from the Greek ischios, hip. Pain in the pelvis and leg was generally called sciatica and attributed to a diseased or subluxated hip:

After protracted attacks of sciatica, when the head of the bone [femur] alternately escapes from and returns into the cavity, an accumulation of synovia occurs. $^{3}$

Hippocrates noticed symptoms which were more frequent in summer and autumn.

In autumn many maladies which occur in summer prevail, besides quartan and erratic fevers, affections of the spleen, dropsy, consumption, strangury, dysentery, sciatica, quinsy, asthma, volvulus, epilepsy, mania, and melancholy.

He treated the condition with warm water applied to the painful area, fumigations, fasting, and subsequently, laxatives and ingestion of boiled milk of the female ass. ${ }^{4}$ Hippocrates showed knowledge of the natural history of sciatica. In the Treatise of the Predictions, he states that in elderly patients with 'cramps and colds at the loin and the legs' the disease would last at least 1 year, whereas young people would get rid of the pain in 40 days - many modern surgeons took all their life to learn this. 4

One hundred years later, Galen recognised abnormal spinal postures and coined the words lordosis, kyphosis, and scoliosis and he attempted to correct them. He treated sciatica by blood letting, to dispose of 'the noxious humours', which he held responsible. 
Caelius Aurelianus (a Roman physician, ca fifth century AD) provided in his work Tardarum sive chronicarum passionum, a remarkably detailed description of the physical exercises and a type of traction in his treatment of sciatica. It was based on his translation of two works of Soranus of Ephesus (98-138 AD), chief of the 'methodist' school of medicine, De morbis acutis et chronicis. The Methodist school was predicated on the theory that attributed all disease to an adverse state of 'internal pores'. Aurelianus, usually considered the greatest Greco-Roman physician after Galen, was familiar with the symptoms of sciatica. He described severe pain emanating from the lower back and radiating into the buttocks, perineum, and even the popliteal fossa, calf, foot, and toes, accompanied by a severe low-back spasm, sensory disturbances, and wasting of the leg. He associated constipation and claudication with the complaint, and noted that sciatica sufferers altered their posture during the defaecation. In some patients, he observed a 'woodenness', a crooked posture, and the inability to bend forward. However, his ideas on the pathology were confused, so that he said, at the height, of the disease, a humour collected that 'corrupted' into pus and produced a multitude of abscesses (possibly tuberculous). He also introduced a form of spinal traction for low back pain.

Aegina is a small Greek island in the Saronic Gulf, 31 miles from Athens where lived Paulus Aegineta (ca 625690), Alexandrian physician and surgeon, the last major ancient Greek medical encyclopaedist, who wrote Epitomae medicae libri septem (Medical Compendium in Seven Books), ${ }^{5}$ which subsumed nearly all medical knowledge of his time. He described sciatica in it, which extended from 'about the buttock and groin to the knee, often as far as the extremities of the foot'; but he confused it with gout. It is clear that like others of this period, no distinction was made between pain arising in the joint and spine. He believed that it was caused by a thick humour that disturbed the articulations of the hip joint.

Few useful concepts or treatments emerged in the dark ages. By the sixteenth and seventeenth centuries, physicians related sciatic pain to turgidity of the veins of the lower limb and treated the disease by bleedings and cautery.

\section{Eighteenth century}

A substantial breakthrough came in 1764, when Domenico Cotugno of Naples, in De Ischiade Nervosa Commentarius $^{6}$ distinguished an 'arthritic sciatica', identifiable with hip pain and a 'nervous sciatica', which was classified as 'postica' (posterior) or 'antica' (anterior). In this crucial work, ${ }^{7}$ Cotugno, an astute clinical observer, differentiated sciatic nerve pain from arthritis of the hip, probably for the first time. The eponym: Cotugno's syndrome, was subsequently applied to unilateral sciatic neuralgia that was generally considered an 'interstitial sciatic neuritis' for the next 150 years.

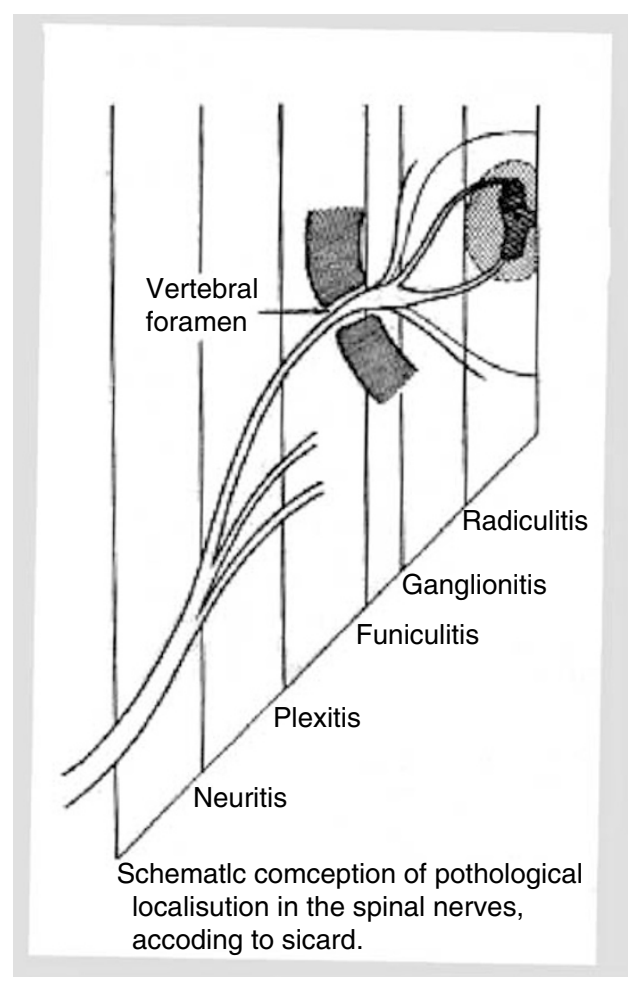

Figure 1 Involvement of roots at intervertebral foramen (Putti, V Lancet 1927)

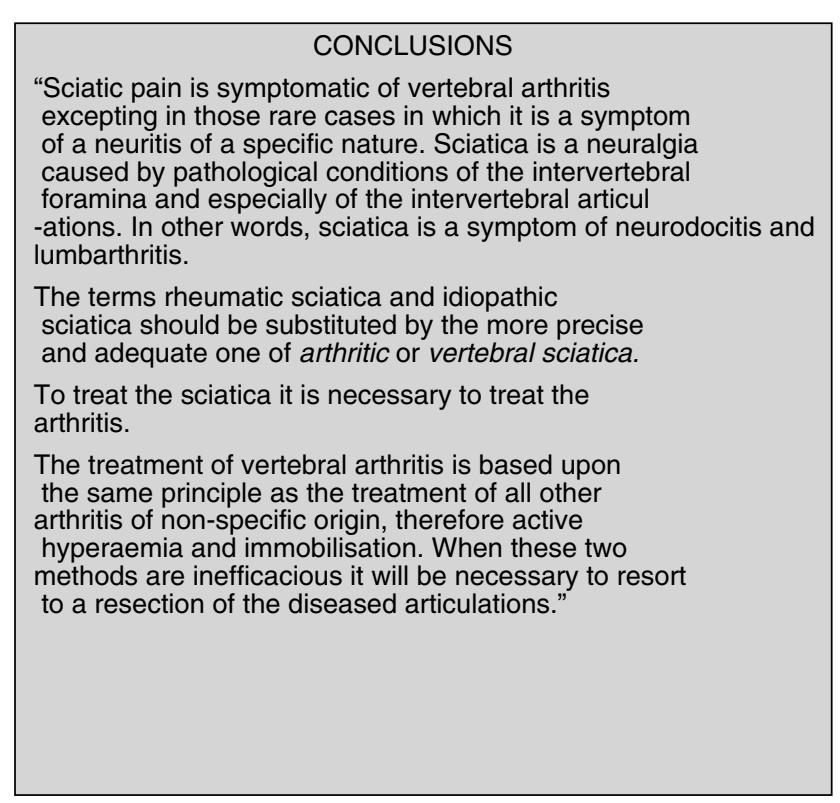

Figure 2 Putti's 1927, vertebral sciatica

Cotugno attributed the symptoms to the presence, in the sheaths of the sciatic nerve, of an acrid matter deriving from the vessels of the sheaths of the nerve, or from the brain itself. To prove the free circulation between the cranial and spinal dura, he stood cadavers on their feet and decapitated them to observe the flow of 
colony-stimulating factor (CSF). He studied 20 adult male cadavers to establish the free circulation between the cranial and spinal dura of cerebrospinal fluid (sometimes referred to as Liquor Cotunnii), his lucid description indicating its formation and absorption from blood vessels. In addition, he noted the incoagulability of CSF in health, but like urine he observed that it became cloudy (due to its high protein content) on boiling, only in disease.

The cerebrospinal water is in perenni statu renovationis, through exudation by minimal arteries and reabsorption by minimal veins. It penetrates into dural sleeves of nerve roots; hence is apt to accumulate in the sheaths of the sciatic nerve and so give pain along its course. Such pain, weakness, and limping may be cured; if necessary by vesicants and caustics to draw out the hydrops. 8

\section{Nineteenth Century}

In the nineteenth century, many European physicians observed herniations of the intervertebral disc during autopsies. Postacchini ${ }^{4}$ refers to: François Valleix (1807-1855) who saw what he called a fractured disc; Von Luschka ${ }^{9}$ identified herniation of the nucleus pulposus. Virchow discussed disc pathology and ruptured discs (known, as 'Virchow's Tumour'). Kocher had reported in 1806, the post mortem disc displacement at L1-L2 in a man who had fallen $100 \mathrm{ft}$. Kocher considered that the protruded intervertebral disc might cause cord compression. But the relation of such lesions to sciatica was not identified then. Lasègue in 1864 described limited straight leg raising in an attempt to distinguish sciatica from hysteria, clearly implicating stretching of the sciatic nerve roots. ${ }^{10,11}$ His former pupil, JJ Forst, published his findings. ${ }^{12}$ In addition, the Serbian physician Laza Lazarevic, ${ }^{13}$ in 1880 described

\section{NBW RNGLAND SURGICAL SOCIETY}

\section{RUPTURE OF THE INTERVERTEBRAL DISC WITH INVOLVEMENT OF THE SPINAL CANAL•}

BT WILLJAS JASON MIXTER, MC.D., $†$ AND JOSEPII S. BARK, X.D. ${ }^{\dagger}$

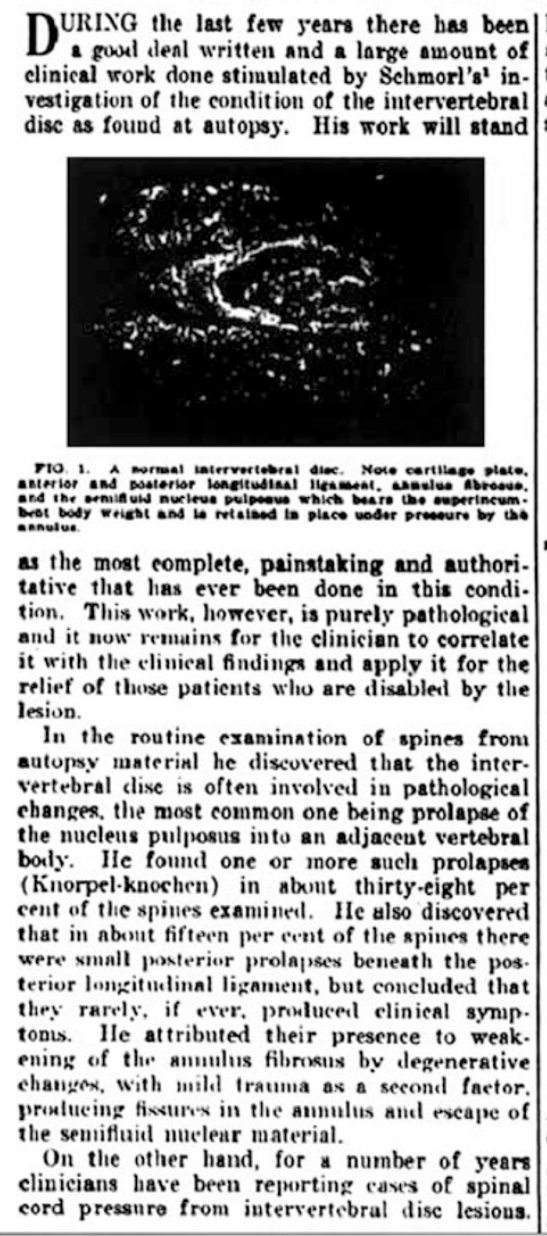

In 1911 Goldthwait ${ }^{2}$ reporterl a case of seintica aud paraplegia which he attribited to a pos.

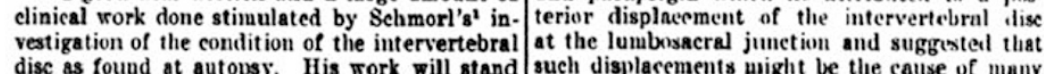
clinical work done stimulated by Schmorl's' in-
vestigation of the condition of the intervertebral
dise as found at autopsy. His mork will stand
such displasements unight be the cause of many disc as found at autopsy. His work will stand

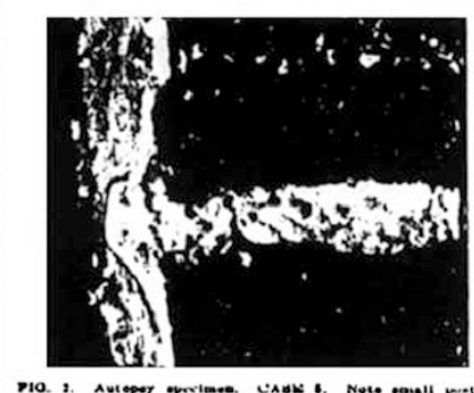

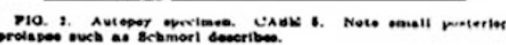

as the most complete, painataking and authoritative that lias ever been done in this condi. tion. This work, however, is purely pathological and it now remains for the clinician to correlate it with the clinical findinge and apply it for the relief

In the routine examination of spines from autonsy material he discovered that the intervertebral clise is often involved in pathological changes, the most common one being prolapse of the nucleus pulposus into an adjaceut vertebral borly. He fonnd one or more such prolapses (Knorpel-knochen) in abuut thirty-eight per cent of the spines examinet. He ylso discovered that in about fifteen per cent of the spines there were small posterior prolapses beneath the pos. terior longitutinal ligament, but concluded that thes rarely, if eter, prohlucesl clinical symp. ening of the aistion filin chanuex, with mild trauma as a second faetor. problucing fixsurex in the anmulus and escape of On the other hand, for a number of years cord pressure from intervertebral disc lesions

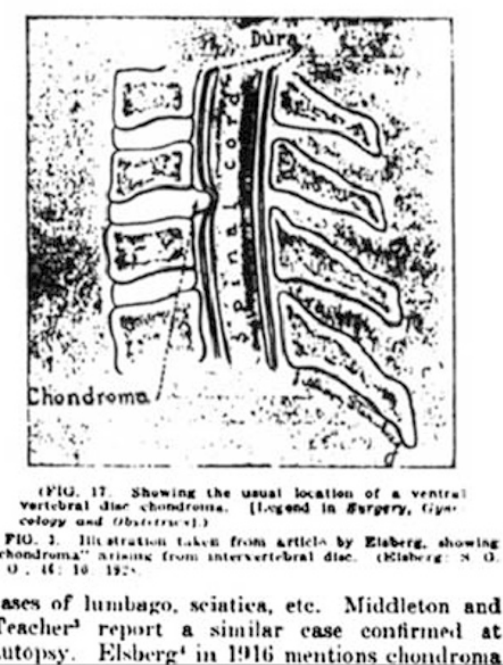

Figure 3 Mixter and Barr's paper, New Engl J Med 1934 
Ischias postica Cotunnii with restricted straight leg raising and sciatic scoliosis.

It is said that AG Smith was the first to perform a laminectomy in 1829 , but I have been unable to trace the details. Sir Victor Horsley is credited with the first laminectomy but this was done for a tumour in 1887 . However, the first successful removal of a ruptured disc was probably in 1901, when Fedor Krause with Herman Oppenheim ${ }^{14}$ described the removal through a low lumbar midline laminectomy of a lesion thought to be an enchondroma. It has subsequently been regarded as a herniated nucleus pulposus.

\section{Twentieth Century}

According to Postacchini ${ }^{4}$ in the year 1900, Davide Giordano performed a laminectomy on a patient who had already undergone numerous treatments, such as syphilitic therapy. He performed a T1 1-L1 laminectomy and sectioned the dorsal nerve roots in a patient probably affected by a prolapsed lumbar disc. Unknown to many, a more limited approach to the spinal canal had been proposed by the Italian Bonomo (1902). ${ }^{15}$

In 1925, Schmorl provided an authoritative and painstaking pathological study, showing the posterior prolapse as well as degeneration of the nucleus pulposus, but the work contained no clinical correlations. An important advance was that of Vittorio Putti, who in 1927 recognised degenerative changes of the intervertebral foramen (Figure 1) as a cause of sciatic compression. ${ }^{16} \mathrm{He}$ used the useful term arthritic or vertebral sciatica. I append (Figure 2) extracts of his conclusions from The Lancet.

In 1934, shortly before Mixter and Barr's paper, Putti operated on a patient with a sequestrated disc without fully realising what he had done. He described this 'strange whitish material inside the canal' and understood that he was dealing with interesting and perhaps not yet known pathology. He sent the specimen to Professor Erdheim in Vienna. The answer was: 'If you could not assure me that you found this material free in the canal and not inside a disc, I would say that it is disc material'. ${ }^{17}$

Walter Dandy described two cases on which he operated for low back and leg pain in 1929. He found cartilaginous fragments lying loose in the spinal canal simulating a spinal tumour. ${ }^{18}$ Calvé and Gallant (cited by Postaccini ${ }^{4}$ ) in 1930 , reported 24 patients with low back pain and sciatica in whom a disc herniation had been found at surgery.

In 1933, Mixter and Barr presented a paper, 'Rupture of the Intervertebral Disc with Involvement of the Spinal Canal' to the New England Surgical Society. This paper, published in 1934 in the New England Journal of Medicine, ${ }^{1}$ was highly influential and opened the era of surgery for disorders of the intervertebral lumbar disc.

The paper (Figure 3) included 19 patients; it related back pain and sciatica to prolapsed or herniated disc material that encroached on the nerve root. It was to change the general notions of sciatica, which despite the

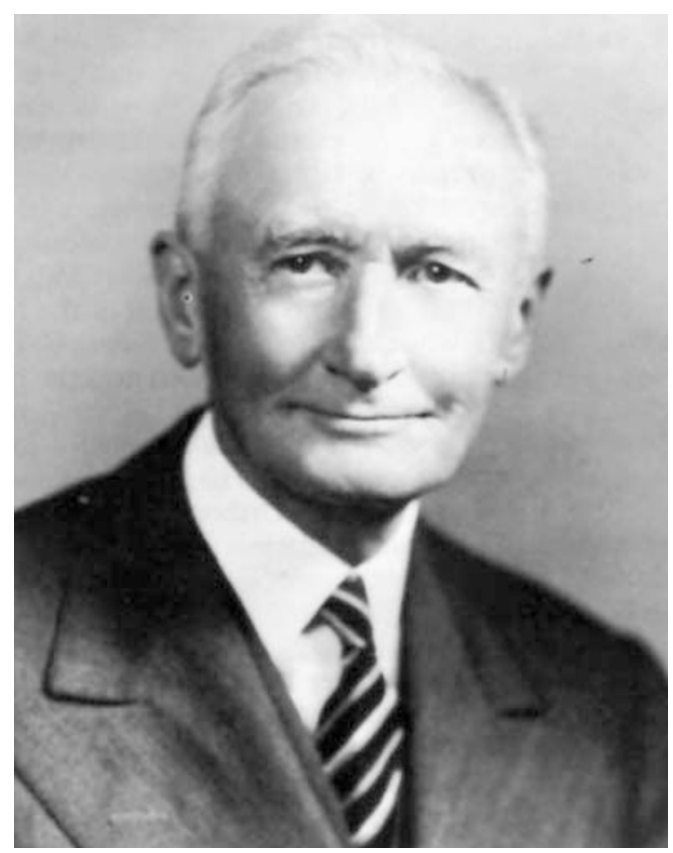

Figure 4 William Jason Mixter

work of Putti and others was held to be most commonly an interstitial neuritis related to emotion, fatigue, or a variety of pelvic and systemic infections. Mixter was generally credited by his contemporaries as being the man who best clarified the relation between the intervertebral disc and sciatica. ${ }^{19}$ Thereafter surgery was widely used, ${ }^{20}$ and many lumbar disc lesions came to the hands of orthopaedic, and less often, neurological surgeons. Many variations of the techniques have developed, sometimes without full appreciation of the natural history of the symptomatology, and the intractability of operative failures. Microdiscectomy ${ }^{21}$ remains the most commonly performed procedure with claimed success rates up to $80 \%$ in skillfully selected cases.

\section{William Jason Mixter (1880-1958)}

Mixter $^{23}$ (Figure 4) grew up in Boston in his family's farm in the Berkshires. He graduated in Biology at the Massachusetts Institute of Technology and entered Harvard Medical School in 1902. After the 1-year internship, he joined his father and brother in private practice.

In 1915, he went to France as a civilian surgeon and cared for the casualties of World War I for 2 years. Later, he was transferred to England as Commanding Officer of Base Hospital 204 at Hursley Park. Although he practised general surgery until 1920, his interest in neurosurgery can be traced back to 1911, when he and his distinguished father were assigned two beds at Massachusetts General Hospital to repeat and assess the techniques developed by Horsley and Cushing. Their success led to Mixter's appointment as First Chief of Neurosurgery in 1933. 
He retired in 1940, but resumed leadership of the Neurosurgical Service during World War II, while his successor, James C White was on active duty. His main work $^{23}$ was devoted to the treatment of pain, the sympathetic nervous system, and the spinal cord. He published papers on many medical topics. ${ }^{19}$

He was elected to the American Surgical Association in 1920 and was one of the original members of the Society of Neurological Surgeons. He trained not less than 28 neurosurgeons.

There are no conflicting interests or financial support in this work. This paper has not been submitted to any other journal.

\section{References}

1 Mixter WJ, Barr JS. Rupture of the intervertebral disc with involvement of the spinal canal. N Engl J Med 1934; 211: 210-214.

2 de Seze S. History of sciatica. Rev Neurol (Paris) 1982; 138: $1019-1025$.

3 Hippocrates. The Genuine Works of Hippocrates (translated by Adams F). W Wood: New York, USA, 1929.

4 Postacchini F. The role of Europe in the spine - past and future perspectives Presidential Lecture, European Spine Society. Eur Spine J 1995; 4: 323-326.

5 Aegineta Paulus. The Seven Books of Paulus (translated by Adams F). Sydenham Society: London 1844.

6 Cotugno D. De ischiade nervosa commentaries. Naples, Simoni, 1764, pp 9-14. Cited by Schiller F (vide supra).

7 Pearce JMS. Domenico Cotugno, CSF and the origins of sciatica. In: Fragments of Neurological History. Imperial College Press: London 2003, pp 211-213.

8 Schiller F. Domenico Cotugno. In: Webb Haymaker and Francis Schiller (eds). The Founders of Neurology, 2nd edn, Charles C Thomas: Springfield, IL 1970, pp 19-23.
9 Luschka H. Von Handbuch der Topographischen Anatomie. Tubingen 1867 (quoted by Fick 1904).

10 Lasègue C. Considérations sur la sciatique. Arch Gen Med $1864,558-560$.

11 Pearce JMS. J-J Forst and Lasègue's Sign. JNNP 1988; 51: 1157.

12 Forst JJ. Contribution to the clinical study of sciatica. Translation of: 'Contribution a l'étude clinique de la sciatique. Thesis. Pour le doctoral en medecine (1881). Arch Neurol 1969; 21: 220-221.

13 Lazarevic LK. Ischias postica Contunnii: Ein Beitrag zu deren Differential-Diagnose. Allg Wien Med Ztg 1884; 29: 425-426 (et seq).

14 Oppenheim H, Krause F. Uber Einklemmung bzw. Strangulation der cauda equine. Dtsch Med Wochenschr 1909; 35: 697-700.

15 Brunori A, De Caro GM, Giuffre R. Surgery of lumbar disk hernia: historical perspective. Ann Ital Chir 1998; 69: 285-293.

16 Putti V. New concepts in the pathogenesis of sciatic pain. Lancet 1927; 2: 54-60.

17 Casuccio PC. Pioneers in Orthopaedics. Vittorio Putti, 1880-1940. http://www.diavlos.gr/orto96/ortowww/euputi.htm.

18 Dandy WE. Loose cartilage from the intervertebral disc simulating tumor of the spinal cord. Arch Surg 1929; 19: 660-662.

19 Parisien RC, Ball PA. William Jason Mixter (1880-1958). Ushering in the 'dynasty of the disc'. Spine 1998; 23: 2363-2366.

20 Patwardhan RV, Hadley MN. History of surgery for ruptured disk. Neurosurg Clin N Am 2001; 12: 173-179.

21 Yasargil MG. Microsurgical operation for herniated lumbar disc. In: Wullenweber R, Brock M, Hamer J, Klinger M, Spoerri O (eds). Advances in Neurosurgery. Springer-Verlag: Berlin 1977, p 81.

22 Neurosurgery at the Massachusetts General Hospital 1909 to 1983 - A Short History and Alumni Record. In: Zervas NT, Neurosurgical Staff (eds). Massachusetts General Hospital - 1st edn, 1984.

23 White JC. William Jason Mixter; 1880-1958. J Neurosurg 1958; 15: 581-584. 